\title{
Co-occurrence of tobacco product use, substance use, and mental health problems among adults: Findings from Wave 1 (2013-2014) of the Population Assessment of Tobacco and Health (PATH) Study*
}

\author{
Kevin P. Conway ${ }^{a}$, Victoria R. Green ${ }^{a, b}$, Karin A. Kaszac ${ }^{c}$, Marushka L. Silveira ${ }^{a, b}$, Nicolette \\ Borek $^{d}$, Heather L. Kimmel ${ }^{\mathrm{a}}$, James D. Sargent ${ }^{\mathrm{e}}$, Cassandra Stanton $^{\mathrm{f}}$, Elizabeth Lambert ${ }^{\mathrm{a}}$, \\ Nahla Hilmi ${ }^{\mathrm{a}, b}$, Chad J. Reissig ${ }^{\mathrm{d}}$, Kia J. Jackson ${ }^{\mathrm{d}}$, Susanne E. Tanski ${ }^{\mathrm{e}}$, David Maklan ${ }^{\dagger}$, \\ Andrew J. Hyland ${ }^{\mathrm{c}}$, and Wilson M. Compton ${ }^{\mathrm{a}}$ \\ aDivision of Epidemiology, Services, and Prevention Research, National Institute on Drug Abuse, \\ National Institutes of Health, Bethesda, MD \\ bKelly Government Solutions, Rockville, MD \\ 'Department of Health Behavior, Roswell Park Cancer Institute, Buffalo, NY \\ 'Office of Science, Center for Tobacco Products, Food and Drug Administration, Silver Spring, \\ MD \\ eCancer Control Research Program, Norris Cotton Cancer Center, Lebanon, NH \\ fWestat, Rockville, MD
}

\begin{abstract}
Background-Although non-cigarette tobacco product use is increasing among U.S. adults, their associations with substance use and mental health problems are unclear. This study examined co-
\end{abstract}

\footnotetext{
* Supplementary material can be found by accessing the online version of this paper at http://dx.doi.org and by entering doi:...

Correspondence: Kevin P. Conway, Ph.D. 6001 Executive Boulevard, Room 5185, Bethesda, MD, 20892, Telephone: (301) 443-6504, Fax: (301) 443-2636, kconway@ nida.nih.gov.

Publisher's Disclaimer: This is a PDF file of an unedited manuscript that has been accepted for publication. As a service to our customers we are providing this early version of the manuscript. The manuscript will undergo copyediting, typesetting, and review of the resulting proof before it is published in its final citable form. Please note that during the production process errors may be discovered which could affect the content, and all legal disclaimers that apply to the journal pertain.

Disclaimer:

The views and opinions expressed in this manuscript are those of the authors only and do not necessarily represent the views, official policy or position of the US Department of Health and Human Services or any of its affiliated institutions or agencies.

Contributors:

Drs. Conway and Compton conceptualized and designed the study and approved the final manuscript as submitted. Dr. Conway, Ms. Green, and Dr. Silveira drafted the initial manuscript and approved the final manuscript as submitted. Ms. Kasza carried out the analyses, reviewed and revised the manuscript, and approved the final manuscript as submitted. Dr. Silveira performed quality assurance and control of the analyses. All others, including Drs. Borek, Kimmel, Sargent, Stanton, Reissig, Jackson, Tanski, Maklan, and Hyland, as well as Ms. Lambert and Hilmi reviewed and approved the initial proposed analyses, reviewed and revised the manuscript, and approved the final manuscript as submitted.
}

Conflict of Interest Statement:

W.M. Compton declares retirement account stock holdings in Pfizer, a manufacturer of tobacco cessation products. No other potential conflicts of interest were reported. 
occurrence of tobacco use, substance use, and mental health problems, and its moderation by gender, among 32,202 U.S. adults from Wave 1 (2013-2014) of the nationally representative longitudinal Population Assessment of Tobacco and Health (PATH) Study.

Methods-Participants self-reported current cigarette, e-cigarette, traditional cigar, cigarillo, filtered cigar, hookah, smokeless tobacco and other tobacco product use; past year alcohol, marijuana, and other drug use; and past year substance use, internalizing and externalizing problems.

Results-Compared to non-current tobacco users, current users were more likely to report alcohol or drug use (adjusted odds ratio $(\mathrm{AOR})=2.6$; 95\% confidence interval $(\mathrm{CI}): 2.3,2.9)$, with the strongest associations observed for cigarillo and hookah users. Across all tobacco product groups, users were more likely to report internalizing ( $\mathrm{AOR}=1.9 ; 95 \% \mathrm{CI}: 1.7,2.1$ ), externalizing $(\mathrm{AOR}=1.6 ; 95 \% \mathrm{CI}: 1.5,1.8)$, and substance use ( $\mathrm{AOR}=3.4 ; 95 \% \mathrm{CI}: 2.9,4.1)$ problems than nonusers. Gender moderated many of these associations and, of these, all non-cigarette tobacco product associations were stronger among females.

Conclusions-This nationally representative study of U.S. adults is the first to comprehensively document tobacco use, substance use, and mental health comorbidities across the range of currently available tobacco products, while also demonstrating that female tobacco users are at increased risk for substance use and mental health problems. These findings may point to gender differences in vulnerability and suggest that interventions incorporate gender-specific approaches.

\section{Keywords}

tobacco; cannabis; mental health; comorbidity; gender; epidemiologic studies

\section{Introduction}

The epidemiology of tobacco use in the United States (U.S.) is evolving, showing declines in adult cigarette use amidst steady use of some tobacco products, such as cigars and smokeless tobacco, and increasing use of other products, such as e-cigarettes and hookah (Agaku et al., 2014). Understanding how these changes in tobacco product use patterns are associated with substance use and mental health problems can strengthen existing tobacco control efforts, particularly in developing focused interventions among these vulnerable populations.

While several cross-sectional studies have explored the associations of some tobacco products and substances used among U.S. adults, none comprehensively examined the range of available tobacco products and substances (Blazer and Wu, 2012; Goodwin et al., 2014a; Zale et al., 2015). One nationally representative study among adults found a strong association between cigarette smoking and nonmedical prescription opioid use (Zale et al., 2015), whereas another study of middle-aged and older adults found that past year cigarette and cigar smokers were more likely to binge drink in comparison to non-smokers (Blazer and $\mathrm{Wu}, 2012)$. A study of college students found a significant association between hookah use and substance use, with the strongest association observed between hookah and alcohol use (Goodwin et al., 2014a). Research on the associations between tobacco use and mental illness among U.S. adults similarly focuses on cigarette use (Smith et al., 2014). A metaanalysis examining the association between cigarette use and depression found that, in cross- 
sectional studies, cigarette smoking was associated with nearly two-fold higher risk of depression compared to never and former smoking (Luger et al., 2014). Other studies focusing predominantly on internalizing (depression and anxiety) disorders produced mixed results. Some studies report that any tobacco product use, including cigarettes, cigars, pipe, and smokeless tobacco, was associated with past year internalizing mental health problems (Blazer and Wu, 2012; Choi et al., 2015), whereas other studies found no significant associations between tobacco use, including cigarette and hookah use, and depression or anxiety (Breslau et al., 1991; Goodwin et al., 2014a). Given the evolving tobacco use patterns among U.S. adults, an assessment of their associations with substance use and mental health problems across the wide range of nicotine delivery systems is warranted.

Gender differences in the prevalence of tobacco use, substance use, and mental health problems among adults have been consistently observed in the general population (Eaton et al., 2012; Office on Smoking and Health, 2001), but scant epidemiologic research has focused on gender differences in the patterns of co-occurrence of tobacco use, substance use, and mental health problems. The few studies examining the moderating effects of gender on these associations have focused only on cigarette use, a major limitation given the diversity of tobacco products available in the marketplace. Regarding the tobacco-substance use association, one study found that male daily cigarette smokers were more likely to report nonmedical prescription opioid use, whereas their female counterparts were more likely to report nonmedical prescription opioid dependence (Zale et al., 2015). Additionally, studies on gender differences in the association between tobacco use and mental health problems have focused mostly on internalizing problems, with equivocal results. One study found that female cigarette smokers were more likely to have current or past depression than male smokers (Husky et al., 2008), whereas another found no gender differences in depression among cigarette smokers, but instead found that female cigarette smokers were more likely than males to have an anxiety disorder (Goodwin et al., 2014b). Expanding this research beyond cigarette smokers may point to unique gender differences and profiles of vulnerability to tobacco product use between males and females (Sinha and Rounsaville, 2002).

Using Wave 1 data from the Population Assessment of Tobacco and Health (PATH) Study, the present study (1) examined co-occurrence of substance use and mental health problems across 10 tobacco products, and (2) examined the moderating effects of gender on these associations.

\section{Methods}

\subsection{Study design}

The PATH Study is a nationally representative, longitudinal cohort study of 45,971 U.S. adults (18 years and older) and youth (12 years and older) examining tobacco use and health. This paper reports Wave 1 (September 2013-December 2014) data from 32,202 adult participants with valid complete data on variables for the specific associations examined (United States Department of Health and Human Services et al., 2016). Participants were recruited via an address-based, area-probability sampling approach, using an in-person household screener to select adults from households that oversampled adult tobacco users, 
young adults, and African American adults. The weighting procedures adjusted for oversampling and nonresponse allowing estimates to be representative of the noninstitutionalized, civilian U.S. population. The weighted response rate among sampled adults was $74.0 \%$.

After consent was obtained, data were collected using Audio-Computer Assisted SelfInterviews administered in English or Spanish. Detailed methodological information about the study design and protocol is available elsewhere (Hyland et al., 2016) and at http:// doi.org/10.3886/ICPSR36231. The study was conducted by Westat and approved by Westat's Institutional Review Board.

\subsection{Measures}

2.2.1. Tobacco use-Self-reported ever use of tobacco products was assessed for the following: cigarettes, e-cigarettes, traditional cigars, cigarillos, filtered cigars, pipe tobacco, hookah, smokeless tobacco (i.e., loose snus, moist snuff, dip, spit, or chewing tobacco), snus pouches, and dissolvable tobacco. A brief description and pictures of each product (except cigarettes) were provided to participants before being asked about the products. Additional questions were asked of cigar users to determine specific cigar type. Participants who had smoked at least 100 cigarettes in their lifetime and who now smoke cigarettes every day or some days were considered 'current established cigarette users'. For all other tobacco products, participants who reported ever use of each tobacco product were asked if they now use the product, and those who use a product every day or some days were considered 'current users'.

'Any current tobacco use' was defined as current use of any tobacco product. 'Any current cigar use' was defined as current use of traditional cigars, cigarillos, or filtered cigars, and 'smokeless including snus' was defined as current use of smokeless tobacco including snus pouches.

2.2.2. Substance use-Ever substance use was assessed for the following substances: alcohol, marijuana (including blunts), misuse of prescription drugs (i.e., Ritalin® or Adderall ${ }^{\circledR}$; painkillers, sedatives, or tranquilizers), cocaine or crack, stimulants (i.e., methamphetamine or speed), heroin, inhalants, solvents, and hallucinogens. Participants who reported ever use of each substance/group of substances were asked how long it had been since their last use; those who had used a substance/group of substances during the past year were considered 'past year users'.

Participants who had consumed alcohol during the past 30 days were asked the average number of alcoholic drinks they consumed per day. 'Problematic alcohol use' was defined as the consumption of an average of 4 or more alcohol drinks per day for females and 5 or more drinks per day for males on the days that participants drank within the past 30 days. This definition is based on the National Institute on Alcohol Abuse and Alcoholism definition of binge drinking (National Institutes of Health (NIH), 2004).

Past year use of other drugs was defined as the use of cocaine or crack stimulants (i.e., methamphetamine or speed), heroin, inhalants, solvents, or hallucinogens during the past 
year. In addition, combined variables were created for past year use of any drug (including and excluding alcohol) and defined as the use of any of these substances during the past year. Substance use items in the PATH Study were adapted from the National Epidemiologic Survey on Alcohol and Related Conditions (National Instiutes of Health (NIH), 2004-2005) and the National Health and Nutrition Examination Survey (Centers for Disease Control and Prevention (CDC), 2011-2012).

2.2.3. Substance use and mental health problems-Substance use and mental health problems were assessed via the Global Appraisal of Individual Needs - Short Screener (GAIN-SS), modified for the PATH Study (Dennis et al., 2006). The GAIN-SS identifies individuals at risk for mental health or substance use disorders using a continuous measure of severity. Items for the GAIN-SS were derived from the full GAIN instrument, a validated, standardized biopsychosocial assessment tool for individuals entering substance abuse or behavioral health treatment (Garner et al., 2013) and recommended for use in epidemiological samples by the PhenX Toolkit (Hamilton et al., 2011). The PATH Study assessed problems across the past year with the number of responses endorsed in the past year summed for each of three subscales: substance use problems, internalizing problems, and externalizing problems. Complete data for subscale components were required. Table 1 displays the items and reliability for each subscale (Tavakol and Dennick, 2011).

Summary scores ranged from $0-7$ for substance use problems, $0-4$ for internalizing problems, and 0-7 for externalizing problems. Participants were categorized into no/low (01 symptoms), moderate (2-3 symptoms), or high (4 symptoms for internalizing problems or $\geq 4$ symptoms for substance use and for externalizing problems) severity based on the number of symptoms endorsed, as informed by previous studies showing concurrent and predictive validity in other samples (Dennis et al., 2006; Garner et al., 2013). While individuals categorized as low severity are unlikely to have a diagnosis or need services, moderate indicates a possible diagnosis and need of services, and high indicates high probabilities of a diagnosis and need for services (Dennis, 2006).

2.2.4. Covariates-Information was collected on socio-demographics including age, gender, race/ethnicity, educational attainment, average household income, and sexual orientation.

\subsection{Statistical Analysis}

Distributions of participants' socio-demographic characteristics, substance use, and symptoms of substance use and mental health problems were examined. All variables were categorized for analyses. For the aggregate variables (e.g., any tobacco use), complete data were required to categorize participants as non-users but not required to categorize participants as users.

Distributions of past year substance use according to current tobacco use overall and by product were examined. Multivariable logistic regression evaluated the associations between tobacco use and substance use, adjusting for socio-demographics. Because of the potential comorbidity between mental health problems and substance use (Conway et al., 2007), a combined variable for mental health (internalizing and externalizing) problems categorized 
as no/low/moderate (0-7 symptoms), and high (8-11 symptoms) was included in the substance use regression models. Separate logistic regression analyses were conducted for each of the tobacco products and substances used.

Distributions of past year symptoms of substance use, internalizing, and externalizing problems according to current tobacco use overall and by product were also examined. Multivariable logistic regression modeled the odds of high versus no/low/moderate substance use problems, internalizing problems, and externalizing problems according to tobacco use, adjusting for socio-demographics. Separate logistic regression analyses were conducted for each of the tobacco products, substance use, internalizing, and externalizing problems.

Moderation by gender was assessed by including interaction terms with tobacco in the final models for substance use, substance use problems, and mental health problems. All estimates were weighted to represent the U.S. adult population; variances and confidence intervals (CIs) were estimated using the balanced repeated replication (BRR) method (McCarthy, 1969) with Fay's adjustment set to 0.3 to increase estimate stability (Judkins, 1990). Adjusted odds ratios (AORs) and 95\% CIs were calculated. Two sided p-values of <. 05 were considered statistically significant. Estimates based on fewer than 50 observations in the denominator or the relative standard error greater than 0.30 were considered statistically unreliable and suppressed (Klein et al., 2002). All analyses were conducted using Stata software, version 12, College Station, TX.

\section{Results}

\subsection{Socio-demographic and other characteristics}

Approximately half of adults were between the ages of 18-44 (47.1\%) and male (48.1\%) (table 2). More than two-thirds of adults (67.7\%) reported using alcohol or any drug in the past year. While alcohol was the most commonly used substance (63.5\%), $11.8 \%$ of adults reported past year use of marijuana. The proportion of adults with past year substance use problems was low $(3.5 \%)$, whereas slightly more adults reported past year internalizing $(11.6 \%)$ and externalizing $(9.3 \%)$ problems.

\subsection{Tobacco use and substance use}

Across all tobacco products, proportions of past year substance use were higher among current tobacco users compared with non-current users (table 3). In multivariable analyses adjusting for socio-demographics and past year mental health (internalizing and externalizing) problems (table 3), current tobacco use was consistently associated with past year substance use across all tobacco products examined. Current tobacco users had a 2.6fold $(95 \%$ CI: $2.3,2.9)$ higher odds of past year alcohol or any drug use when compared to non-current users, with the strongest association observed for current use of cigarillos $(\mathrm{AOR}=4.5 ; 95 \% \mathrm{CI}: 3.8,5.3)$ and hookah $(\mathrm{AOR}=4.0$; 95\% CI: 3.3, 4.7). Current tobacco use was associated with a 4.4-fold (95\% CI: 4.0-4.9) higher odds of past-year marijuana use compared to non-current users, with the strongest associations observed for current cigarillo $(\mathrm{AOR}=4.7 ; 95 \% \mathrm{CI}: 4.2,5.1)$ and hookah $(\mathrm{AOR}=4.5 ; 95 \% \mathrm{CI}: 4.0,5.1)$ users. In contrast,

Drug Alcohol Depend. Author manuscript; available in PMC 2018 August 01. 
the strongest associations for past year problematic alcohol use (AOR=3.0; 95\% CI: 2.6, 3.3), Ritalin/Adderall ( $\mathrm{AOR}=3.2 ; 95 \% \mathrm{CI}: 2.7,3.9$ ), painkillers/sedatives ( $\mathrm{AOR}=2.0 ; 95 \%$ CI: $1.8,2.2)$, and other drugs ( $\mathrm{AOR}=4.4 ; 95 \% \mathrm{CI}: 3.7,5.2)$ were observed among current established cigarette users.

Gender significantly moderated the association between tobacco use and past year substance use for some tobacco products and substances assessed. Specifically, stronger associations with substance use were observed among females compared to males for current use of noncigarette tobacco products, including the different types of cigars. In contrast, the associations between current established cigarette use and past year substance use were slightly stronger among males compared to females (any drug use (excl. alcohol): AOR=3.1; 95\% CI: 2.7, 3.5 among males (supplemental table $1^{1}$ ) versus AOR= 2.8; 95\% CI: $2.5,3.2$ among females (supplemental table $\left.2^{1}\right)$ ).

Gender-by-cigar use interactions were notably strong for past year marijuana use, with the odds ratios for females (AOR=4.7; 95\% CI: 3.5, 6.3 for traditional cigars, $\mathrm{AOR}=8.5 ; 95 \%$ CI: $6.8,10.5$ for cigarillos, and AOR=3.7; $95 \% \mathrm{CI}$ : $2.8,4.8$ for filtered cigars) almost double those for males $(\mathrm{AOR}=2.4 ; 95 \% \mathrm{CI}: 2.1,2.7$ for traditional cigars, $\mathrm{AOR}=3.8 ; 95 \% \mathrm{CI}: 3.4$, 4.2 for cigarillos, and $\mathrm{AOR}=2.1 ; 95 \% \mathrm{CI}: 1.8,2.5$ for filtered cigars). Finally, significant gender-by-hookah use interactions were observed for past year alcohol and problematic alcohol use with stronger associations observed among females (AOR=3.1; 95\% CI: 2.5, 3.9 and $\mathrm{AOR}=2.9 ; 95 \% \mathrm{CI}: 2.4,3.6$, respectively) compared to males ( $\mathrm{AOR}=2.5 ; 95 \% \mathrm{CI}: 2.0$, 3.1 and $\mathrm{AOR}=1.9 ; 95 \% \mathrm{CI}: 1.6,2.3$, respectively).

\subsection{Tobacco use and substance use and mental health problems}

Current tobacco users, compared to non-current users, were more likely to report high severity substance use problems ( $9.0 \%$ vs. $1.9 \%)$, internalizing problems ( $20.1 \%$ vs. $9.2 \%)$, and externalizing problems (15.6\% vs. $7.9 \%)$ in the past year (table 4$)$.

Across all tobacco products assessed, multivariable logistic regression models showed significant associations between current tobacco use and past year substance use problems after adjusting for socio-demographics (table 4). Current tobacco use was associated with a 3.4-fold (95\% CI: 2.9, 4.1) higher odds of substance use problems in the past year, with the strongest associations observed for current established cigarette users ( $\mathrm{AOR}=3.5 ; 95 \% \mathrm{CI}$ : $3.0,4.0$ ) and current hookah users (AOR=2.9; 95\% CI: 2.4, 3.4). Similarly, current tobacco use was consistently associated with mental health problems across the tobacco products, but compared with substance use problems, associations were not as strong for internalizing $(\mathrm{AOR}=1.9 ; 95 \% \mathrm{CI}: 1.7,2.1)$ and externalizing $(\mathrm{AOR}=1.6 ; 95 \% \mathrm{CI}: 1.5,1.8)$ problems.

Comparable to substance use, gender significantly moderated the association between tobacco use and substance use problems with a stronger association observed among females $\left(\mathrm{AOR}=4.9 ; 95 \% \mathrm{CI}: 3.7,6.5\right.$, supplemental table $\left.3^{2}\right)$ compared to males $(\mathrm{AOR}=2.8 ; 95 \% \mathrm{CI}$ : 2.3, 3.6, supplemental table $4^{2}$ ). Across tobacco products, the association between current

\footnotetext{
${ }^{1}$ Supplementary material can be found by accessing the online version of this paper at http://dx.doi.org and by entering doi:...

${ }^{2}$ Supplementary material can be found by accessing the online version of this paper at http://dx.doi.org and by entering doi:...
} 
cigar use, as well as current hookah use, and substance use problems were consistently stronger among females.

Similar consistent gender differences were also observed in the associations between tobacco use and mental health problems. Specifically, the associations of current e-cigarette use and current traditional cigar use with internalizing problems were stronger among females compared to males. In addition, while male cigarette users had a 1.5-fold (95\% CI: $1.3,1.7)$ higher likelihood of reporting externalizing problems compared to non-current users, female cigarette users had a two-fold higher likelihood of reporting externalizing problems (95\% CI: 1.7, 2.3).

\section{Discussion}

This study is the first to document the co-occurrence of substance use, mental health problems, and tobacco use across the range of currently available tobacco products in a nationally representative sample of U.S. adults. Several findings have emerged that warrant further discussion. First, tobacco users were significantly more likely to use alcohol or any drug compared to non-tobacco users, and these findings were robust across substances. Second, tobacco users were more likely to report substance use, internalizing and externalizing problems compared to non-users, with the strongest associations for substance use problems. Third, gender moderated many of these associations, suggesting greater vulnerability to substance use as well as substance use and mental health problems for female non-cigarette tobacco users.

The consistent strength of associations across tobacco products with substance use supports the robustness of these comorbidities irrespective of different nicotine delivery mechanisms. However, there was a notable clustering of associations between certain tobacco products and certain substances. For example, in comparison to other tobacco product users, cigarette users had the strongest likelihood of problematic alcohol and other drug use, while cigarillo users had the highest likelihood of alcohol and marijuana use. Of note were the consistent, strong associations of hookah use with alcohol, marijuana, Ritalin ${ }^{\circledR} /$ Adderall $^{\circledR}$, and other drugs, which were often the strongest in comparison to other tobacco product users. These results suggest hookah use as a potential indicator of polysubstance use, which has been linked to a more serious course of substance use and related adverse outcomes (Connor et al., 2014). These findings not only extend the literature that to date has been limited to associations of certain tobacco products with certain substances (Blazer and Wu, 2012; Goodwin et al., 2014a; Zale et al., 2015), but also point to use patterns that warrant further attention. Of particular concern is the co-occurring use of cigars and marijuana, which may pose additive risk for toxicant exposure (Meier and Hatsukami, 2016).

Compared to non-users, tobacco users across different tobacco products were more likely to have mental health and substance use problems. These findings add to the literature that has focused primarily upon associations between tobacco use and internalizing problems (Blazer and $\mathrm{Wu}, 2012$; Breslau et al., 1991; Choi et al., 2015; Goodwin et al., 2014a; Luger et al., 2014) by documenting tobacco-product specific associations with substance use problems and externalizing problems. In comparing tobacco user groups, associations of tobacco use 
with substance use problems and internalizing problems were strongest for cigarette users, while associations between tobacco use and externalizing problems were strongest for cigarillo users. This finding suggests that cigarillo use may be a potential marker of attentional problems or an underlying trait (e.g., behavioral dysregulation) that has been linked with externalizing behaviors more generally (Krueger et al., 2007; Krueger et al., 2005).

The gender differences that emerged for both substance use and mental health problem associations add to the literature that has focused primarily on gender differences in the association between cigarette smoking and internalizing problems (Goodwin et al., 2014b; Husky et al., 2008). While male cigarette smokers were more likely than females to use any drug, female users of traditional cigars, cigarillos, and filtered cigars were more likely to use marijuana than their male counterparts. Further, female tobacco users, particularly cigar and hookah users, were more likely to report substance use problems. Results were similar for internalizing and externalizing problems; compared to male users, female e-cigarette and traditional cigar users were more likely to have internalizing problems and female cigarette users were more likely to have externalizing problems. These findings point to potential etiological or biological differences in addiction and comorbidity between males and females (Becker and Hu, 2008; Bobzean et al., 2014; Cross et al., 2017; Greenfield et al., 2010; Vanyukov et al., 2012) and have important implications for assessing preventive and treatment interventions traditionally designed for men and based predominantly on male norms (Greenfield et al., 2010).

Our results should be evaluated with regard to strengths and limitations. While the GAIN-SS measures mental health symptomology rather than diagnosis, the high sensitivity and specificity between GAIN items and diagnoses supports their use as good indicators of clinically significant mental health problems (Dennis et al., 2006). Additionally, the omission of some items (e.g., suicidality) from the GAIN-SS from the PATH Study's Wave 1 instrument limited the ability to assess their associations with tobacco use. The instrument also precluded specific examination of prescription opioid misuse, a limitation of this study in light of the current opioid epidemic. While this study did not test if associations varied by exclusive vs. poly-use of tobacco products and other substances, future studies that focus on this issue may identify groups of users who are at particularly high risk for substance use or mental health problems. Furthermore, while this study did not test interactions with other demographic variables, future studies may explore comorbidities across different subgroups defined by demographics (e.g., age, race/ethnicity) as well as use patterns, such as concurrent users of tobacco and marijuana (e.g., blunt use). Moreover, future studies may also provide insight into the mechanisms that underlie the associations observed in this study. When available, the longitudinal PATH Study data will help clarify the temporal ordering between adult tobacco use, substance use, and substance use and mental health problems, while also allowing for further understanding on the role of gender in this dynamic. Finally, our results cannot be generalized to the institutionalized population (e.g., hospitalized or incarcerated individuals) due to the exclusion of this population at Wave 1. 


\title{
4.1. Conclusions
}

In this nationally representative sample of U.S. adults, tobacco users were more likely to use substances and have mental health problems, especially among females. This study revealed substance use and mental health comorbidities across tobacco products beyond the currently documented associations with cigarette use and further highlighted gender differences between these comorbidities. These findings have important bearings on developing, implementing, and evaluating tobacco control interventions for vulnerable populations in the current tobacco landscape.

\section{Supplementary Material}

Refer to Web version on PubMed Central for supplementary material.

\section{Acknowledgments}

\author{
Author Disclosures \\ Role of Funding Source:
}

This manuscript is supported with Federal funds from the National Institute on Drug Abuse, National Institutes of Health, and the Food and Drug Administration, Department of Health and Human Services, under a contract to Westat (Contract No. HHSN271201100027C).

\section{References}

Agaku IT, King BA, Husten CG, Bunnell R, Ambrose BK, Hu SS, Holder-Hayes E, Day HR. Tobacco product use among adults-United States, 2012-2013. MMWR Morb Mortal Wkly Rep. 2014; 63:542-547. [PubMed: 24964880]

Becker JB, Hu M. Sex differences in drug abuse. Front Neuroendocrinol. 2008; 29:36-47. [PubMed: 17904621]

Blazer DG, Wu LT. Patterns of tobacco use and tobacco-related psychiatric morbidity and substance use among middle-aged and older adults in the United States. Aging Ment Health. 2012; 16:296304. [PubMed: 22292514]

Bobzean SA, DeNobrega AK, Perrotti LI. Sex differences in the neurobiology of drug addiction. Exp Neurol. 2014; 259:64-74. [PubMed: 24508560]

Breslau N, Kilbey M, Andreski P. Nicotine dependence, major depression, and anxiety in young adults. Arch Gen Psychiatry. 1991; 48:1069-1074. [PubMed: 1845224]

National Center for Health Statistics. , editor. Centers for Disease Control and Prevention (CDC). National Health and Nutrition Examination Survey Questionnaire (NHANES). Hyattsville, MD: 2011-2012.

Choi NG, DiNitto DM, Marti CN. Alcohol and other substance use, mental health treatment use, and perceived unmet treatment need: Comparison between baby boomers and older adults. Am J Addict. 2015; 24:299-307. [PubMed: 25923291]

Connor JP, Gullo MJ, White A, Kelly AB. Polysubstance use: Diagnostic challenges, patterns of use and health. Curr Opin Psychiatry. 2014; 27:269-275. [PubMed: 24852056]

Conway KP, Montoya ID, Compton WM. Lifetime Psychiatric Comorbidity of Illicit Drug Use Disorders. Psychiatric Times. 2007

Cross SJ, Linker KE, Leslie FM. Sex-dependent effects of nicotine on the developing brain. J Neurosci Res. 2017; 95:422-436. [PubMed: 27870426]

Dennis ML, Chan YF, Funk RR. Development and validation of the GAIN Short Screener (GSS) for internalizing, externalizing and substance use disorders and crime/violence problems among adolescents and adults. Am J Addict. 2006; 15(Suppl 1):80-91. [PubMed: 17182423]

Drug Alcohol Depend. Author manuscript; available in PMC 2018 August 01. 
Dennis, ML., Feeney, T., Stevens, LH., Bedoya, L. Global Appraisal of Individual Needs-Short Screener (GAIN-SS): Administration and Scoring Manual for the GAIN-SS Version 2.0.3. Chestnut Health Systems; Bloomington, IL: 2006.

Eaton NR, Keyes KM, Krueger RF, Balsis S, Skodol AE, Markon KE, Grant BF, Hasin DS. An invariant dimensional liability model of gender differences in mental disorder prevalence: Evidence from a national sample. J Abnorm Psychol. 2012; 121:282-288. [PubMed: 21842958]

Garner BR, Belur VK, Dennis ML. The GAIN Short Screener (GSS) as a Predictor of Future Arrest or Incarceration Among Youth Presenting to Substance Use Disorder (SUD) Treatment. Subst Abuse. 2013; 7:199-208. [PubMed: 24348045]

Goodwin RD, Grinberg A, Shapiro J, Keith D, McNeil MP, Taha F, Jiang B, Hart CL. Hookah use among college students: Prevalence, drug use, and mental health. Drug Alcohol Depend. 2014a; 141:16-20. [PubMed: 24882367]

Goodwin RD, Wall MM, Choo T, Galea S, Horowitz J, Nomura Y, Zvolensky MJ, Hasin DS. Changes in the prevalence of mood and anxiety disorders among male and female current smokers in the United States: 1990-2001. Ann Epidemiol. 2014b; 24:493-497. [PubMed: 24935462]

Greenfield SF, Back SE, Lawson K, Brady KT. Substance abuse in women. Psychiatr Clin North Am. 2010; 33:339-355. [PubMed: 20385341]

Hamilton CM, Strader LC, Pratt JG, Maiese D, Hendershot T, Kwok RK, Hammond JA, Huggins W, Jackman D, Pan H, Nettles DS, Beaty TH, Farrer LA, Kraft P, Marazita ML, Ordovas JM, Pato CN, Spitz MR, Wagener D, Williams M, Junkins HA, Harlan WR, Ramos EM, Haines J. The PhenX Toolkit: Get the most from your measures. Am J Epidemiol. 2011; 174:253-260. [PubMed: 21749974]

Husky MM, Mazure CM, Paliwal P, McKee SA. Gender differences in the comorbidity of smoking behavior and major depression. Drug Alcohol Depend. 2008; 93:176-179. [PubMed: 17850991]

Hyland A, Ambrose BK, Conway KP, Borek N, Lambert E, Carusi C, Taylor K, Crosse S, Fong GT, Cummings KM, Abrams D, Pierce JP, Sargent J, Messer K, Bansal-Travers M, Niaura R, Vallone D, Hammond D, Hilmi N, Kwan J, Piesse A, Kalton G, Lohr S, Pharris-Ciurej N, Castleman V, Green VR, Tessman G, Kaufman A, Lawrence C, van Bemmel DM, Kimmel HL, Blount B, Yang L, O’Brien B, Tworek C, Alberding D, Hull LC, Cheng Y-C, Maklan D, Backinger CL, Compton WM. Design and methods of the Population Assessment of Tobacco and Health (PATH) Study. Tob Control. 2016 Published Online First: 08 August 2016.

Judkins DR. Fay's method for variance estimation. J Off Stat. 1990; 6:223-239.

Klein, RJ., Proctor, SE., Boudreault, MA., Turczyn, KM. Healthy People 2010 criteria for data suppression. National Center for Health Statistics; Hyattsville, Maryland: 2002. p. 1-12.Statistical Notes, no. 24

Krueger RF, Markon KE, Patrick CJ, Benning SD, Kramer MD. Linking antisocial behavior, substance use, and personality: an integrative quantitative model of the adult externalizing spectrum. $\mathbf{J}$ Abnorm Psychol. 2007; 116:645-666. [PubMed: 18020714]

Krueger RF, Markon KE, Patrick CJ, Iacono WG. Externalizing psychopathology in adulthood: a dimensional-spectrum conceptualization and its implications for DSM-V. J Abnorm Psychol. 2005; 114:537-550. [PubMed: 16351376]

Luger TM, Suls J, Vander Weg MW. How robust is the association between smoking and depression in adults? A meta-analysis using linear mixed-effects models Addict Behav. 2014; 39:1418-1429. [PubMed: 24935795]

McCarthy PJ. Pseudoreplication: Further evaluation and applications of the balanced half-sample technique. Vital Health Stat. 1969; 2:1-24.

Meier E, Hatsukami DK. A review of the additive health risk of cannabis and tobacco co-use. Drug Alcohol Depend. 2016; 166:6-12. [PubMed: 27476751]

National Institutes of Health (NIH). National Institute of Alcohol Abuse and Alcoholism (NIAAA) Newsletter (NIH publication number 04-5346). 2004

National Institute on Alcohol Abuse and Alcoholism (NIAAA), , editor. National Instiutes of Health (NIH). National Epidemiologic Survey on Alcohol and Related Conditions (NESARC). Rockville, MD: 2004-2005. 
Office on Smoking and Health. Publications and Reports of the Surgeon General Women and Smoking: A Report of the Surgeon General. Centers for Disease Control and Prevention (US); Atlanta (GA): 2001.

Sinha R, Rounsaville BJ. Sex differences in depressed substance abusers. J Clin Psychiatry. 2002; 63:616-627. [PubMed: 12143921]

Smith PH, Mazure CM, McKee SA. Smoking and mental illness in the U.S. population. Tob Control. 2014; 23:e147-153. [PubMed: 24727731]

Tavakol M, Dennick R. Making sense of Cronbach's alpha. Int J Med Educ. 2011; 2:53-55. [PubMed: 28029643]

United States Department of Health and Human Services, National Institutes of Health, National Institute on Drug Abuse. Population Assessment of Tobacco and Health (PATH) Study [United States]. Inter-university Consortium for Political and Social Research; Ann Arbor, MI: 2016. United States Department of Health and Human Services, Food and Drug Administration, Center for Tobacco Products. Restricted-Use Files. ICPSR36231

Vanyukov MM, Tarter RE, Kirillova GP, Kirisci L, Reynolds MD, Kreek MJ, Conway KP, Maher BS, Iacono WG, Bierut L, Neale MC, Clark DB, Ridenour TA. Common liability to addiction and "gateway hypothesis": Theoretical, empirical and evolutionary perspective. Drug Alcohol Depend. 2012; 123:S3-17. [PubMed: 22261179]

Zale EL, Dorfman ML, Hooten WM, Warner DO, Zvolensky MJ, Ditre JW. Tobacco Smoking, Nicotine Dependence, and Patterns of Prescription Opioid Misuse: Results From a Nationally Representative Sample. Nicotine Tob Res. 2015; 17:1096-1103. [PubMed: 25344958] 


\section{Highlights}

- Compared to non-users, tobacco users are more likely to use alcohol or any drug.

- $\quad$ Female non-cigarette tobacco users are more likely to use drugs.

- Tobacco users are more likely to have substance use and mental health problems.

- Female tobacco users are more likely to have substance and mental health problems. 


\section{Table 1}

GAIN-SS Items and Reliability.

\begin{tabular}{|c|c|c|}
\hline GAIN-SS Subscale & Items & Reliability $a$ \\
\hline \multirow[t]{7}{*}{ Substance Use Problem Symptoms $b, c$} & 1) Used alcohol or other drugs weekly or more often & Past year $=0.77$ \\
\hline & 2) Spent a lot of time getting alcohol or other drugs $d$ & \multirow{6}{*}{ Lifetime $=0.84$} \\
\hline & 3) Spent a lot of time using or recovering $d$ & \\
\hline & 4) Alcohol or drugs causing social problems, fights, or trouble with others & \\
\hline & 5) Reduced involvement with activities at work, school, home, or social events & \\
\hline & 6) Withdrawal problems $d$ & \\
\hline & 7) Use of alcohol or other drugs to stop being sick or avoid withdrawal problems $d$ & \\
\hline \multirow[t]{4}{*}{ Internalizing Problem Symptoms $b, e$} & 1) Feeling very trapped/sad/depressed & \multirow[t]{2}{*}{ Past year $=0.82$} \\
\hline & 2) Trouble sleeping & \\
\hline & 3) Feeling nervous/anxious/tense/scared & \multirow[t]{2}{*}{ Lifetime $=0.84$} \\
\hline & 4) Being distressed/upset about the past & \\
\hline \multirow[t]{7}{*}{ Externalizing Problem Symptoms $b$} & 1) Hard time paying attention & \multirow[t]{2}{*}{ Past year $=0.72$} \\
\hline & 2) Hard time listening to instructions & \\
\hline & 3) Lied/conned to get something & \multirow[t]{5}{*}{ Lifetime $=0.79$} \\
\hline & 4) Bullied/threatened people & \\
\hline & 5) Started a physical fight & \\
\hline & 6) Felt restless/need to climb on things $f$ & \\
\hline & 7) Gave answers before question was finished $f$ & \\
\hline \multicolumn{3}{|c|}{ bbreviations: GAIN-SS, Global Appraisal of Individual Needs - Short Screener } \\
\hline \multicolumn{3}{|c|}{ Cronbach's a calculated for the PATH Study cutpoints. } \\
\hline \multicolumn{3}{|c|}{ 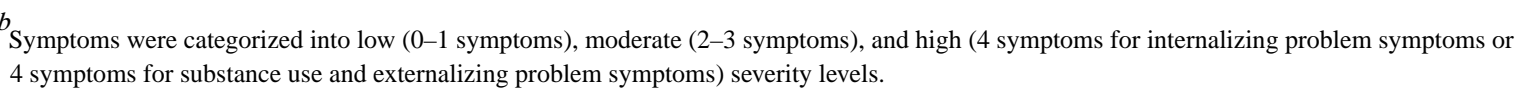 } \\
\hline \multicolumn{3}{|c|}{ 'Those who had never used alcohol or drugs were coded as having ' 0 ' symptoms } \\
\hline \multicolumn{3}{|c|}{ Items 2 and 3, as well as 6 and 7, were separated in the PATH Study. } \\
\hline
\end{tabular}

Drug Alcohol Depend. Author manuscript; available in PMC 2018 August 01. 
Table 2

Demographic and Other Characteristics of Adults in the PATH Study, United States, 2013-2014.

\begin{tabular}{|c|c|c|c|}
\hline Participant Characteristics & $\mathrm{n}^{a}$ & $\% b$ & $\mathbf{S E}^{b}$ \\
\hline Total & 32,202 & 100.0 & \\
\hline \multicolumn{4}{|l|}{ Age (years) } \\
\hline $18-24$ & 9,093 & 13.0 & 0.01 \\
\hline $25-34$ & 6,315 & 17.8 & 0.23 \\
\hline $35-44$ & 4,918 & 16.6 & 0.23 \\
\hline $45-54$ & 4,822 & 17.9 & 0.20 \\
\hline $55-64$ & 3,950 & 16.5 & 0.20 \\
\hline $65+$ & 3,093 & 18.2 & 0.03 \\
\hline \multicolumn{4}{|l|}{ Gender } \\
\hline Male & 16,241 & 48.1 & 0.03 \\
\hline Female & 15,933 & 51.9 & 0.03 \\
\hline \multicolumn{4}{|l|}{ Race/ethnicity } \\
\hline White, non-Hispanic & 19,237 & 66.0 & 0.07 \\
\hline Black or African-American, non-Hispanic & 4,474 & 11.2 & 0.05 \\
\hline American Indian/Alaska Native, non-Hispanic & 194 & 0.3 & 0.06 \\
\hline Asian/Native Hawaiian/Other Pacific Islander, non-Hispanic & 962 & 5.3 & 0.08 \\
\hline Multiple races, non-Hispanic & 1,267 & 1.9 & 0.06 \\
\hline Hispanic & 5,520 & 15.3 & 0.03 \\
\hline \multicolumn{4}{|l|}{ Education (Grade in School) } \\
\hline Less than high school & 1432 & 4.5 & 0.13 \\
\hline Some high school, no diploma & 2,791 & 7.1 & 0.15 \\
\hline GED & 2,212 & 5.1 & 0.15 \\
\hline High school graduate with diploma & 7,533 & 24.4 & 0.06 \\
\hline Some college, no degree & 8,012 & 20.6 & 0.21 \\
\hline Associate degree - occupational/vocational & 1,771 & 5.6 & 0.16 \\
\hline Associate degree - academic program & 1,498 & 4.9 & 0.17 \\
\hline Bachelor's degree & 4,490 & 17.8 & 0.07 \\
\hline Master's degree or more & 2,300 & 10.1 & 0.04 \\
\hline \multicolumn{4}{|l|}{ Household income } \\
\hline Less than $\$ 10,000$ & 5,663 & 13.7 & 0.25 \\
\hline$\$ 10,000$ to $\$ 14,999$ & 3,160 & 8.8 & 0.22 \\
\hline$\$ 15,000$ to $\$ 24,999$ & 3,603 & 11.6 & 0.30 \\
\hline$\$ 25,000$ to $\$ 34,999$ & 3,229 & 10.6 & 0.28 \\
\hline$\$ 35,000$ to $\$ 49,999$ & 3,432 & 12.4 & 0.29 \\
\hline$\$ 50,000$ to $\$ 74,999$ & 3,718 & 14.5 & 0.34 \\
\hline$\$ 75,000$ to $\$ 99,999$ & 2,416 & 10.4 & 0.34 \\
\hline$\$ 100,000+$ & 3,911 & 18.0 & 0.47 \\
\hline \multicolumn{4}{|l|}{ Sexual orientation } \\
\hline Straight & 29,324 & 95.1 & 0.16 \\
\hline
\end{tabular}

Drug Alcohol Depend. Author manuscript; available in PMC 2018 August 01. 


\begin{tabular}{|c|c|c|c|}
\hline Participant Characteristics & $\mathrm{n}^{a}$ & $\% b$ & $\mathrm{SE}^{b}$ \\
\hline Bisexual & 1,079 & 2.1 & 0.09 \\
\hline Gay or lesbian & 632 & 1.5 & 0.10 \\
\hline Something else & 466 & 1.3 & 0.09 \\
\hline \multicolumn{4}{|l|}{ Past year substance use ${ }^{c}$} \\
\hline Alcohol or any drug & 23,630 & 67.7 & 0.78 \\
\hline Any drug (excluding alcohol) & 9,037 & 18.1 & 0.38 \\
\hline Alcohol & 22,027 & 63.5 & 0.80 \\
\hline Problematic Alcohol & 3,907 & 7.5 & 0.19 \\
\hline Marijuana & 6,973 & 11.8 & 0.32 \\
\hline Ritalin/Adderall & 845 & 1.3 & 0.07 \\
\hline Painkillers/Sedatives & 3,162 & 7.8 & 0.22 \\
\hline Other Drugs $d$ & 1,184 & 2.0 & 0.08 \\
\hline \multicolumn{4}{|l|}{ Past year substance use problems ${ }^{e}$} \\
\hline Low & 24,627 & 85.2 & 0.30 \\
\hline Moderate & 4,911 & 11.3 & 0.26 \\
\hline High & 1,944 & 3.5 & 0.12 \\
\hline \multicolumn{4}{|l|}{ Past year internalizing problems $e$} \\
\hline Low & 19,177 & 67.7 & 0.41 \\
\hline Moderate & 7,410 & 20.7 & 0.33 \\
\hline High & 5,301 & 11.6 & 0.27 \\
\hline \multicolumn{4}{|l|}{ Past year externalizing problems $e$} \\
\hline Low & 19,399 & 68.8 & 0.35 \\
\hline Moderate & 7,794 & 21.8 & 0.31 \\
\hline High & 4,367 & 9.3 & 0.23 \\
\hline
\end{tabular}

Abbreviations: SE, standard error; GED, general educational development

${ }^{a}$ Represents unweighted sample size (numbers may not sum to the total due to missing data)

$b_{\text {Percentages (\%) and standard errors (SE) are weighted to represent the US adult population }}$

${ }^{c}$ Categories are not mutually exclusive (i.e., percentages do not sum to $\left.100 \%\right)$

$d_{\text {Includes past year use of cocaine or crack, stimulants (i.e., methamphetamine or speed), or heroin, inhalants, solvents, or hallucinogens }}$

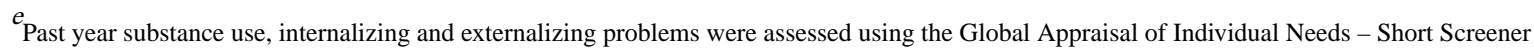
(GAIN-SS) categorized as low (0-1 symptoms), moderate (2-3 symptoms), and high (4 symptoms for internalizing problems or $\geq 4$ symptoms for substance use and externalizing problems) severity levels

Drug Alcohol Depend. Author manuscript; available in PMC 2018 August 01. 


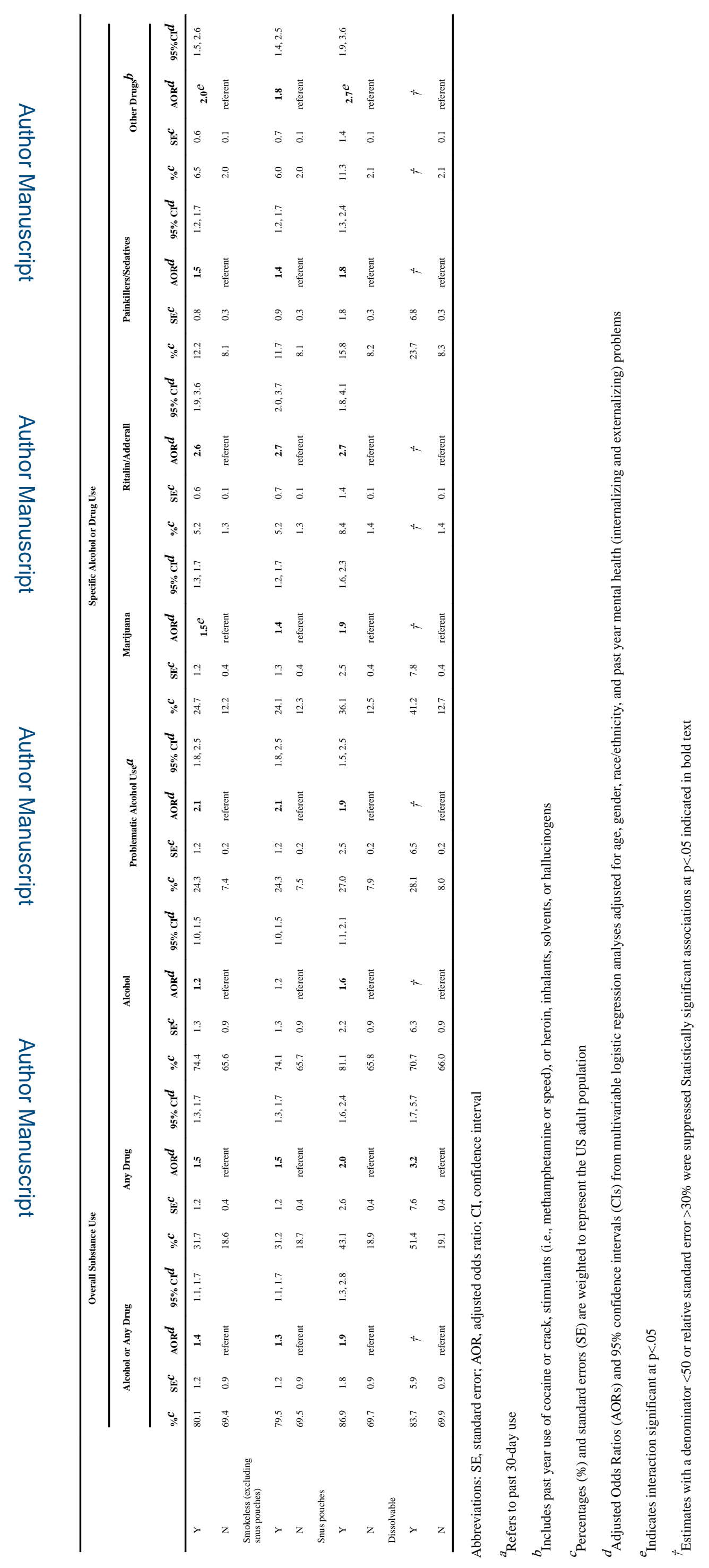




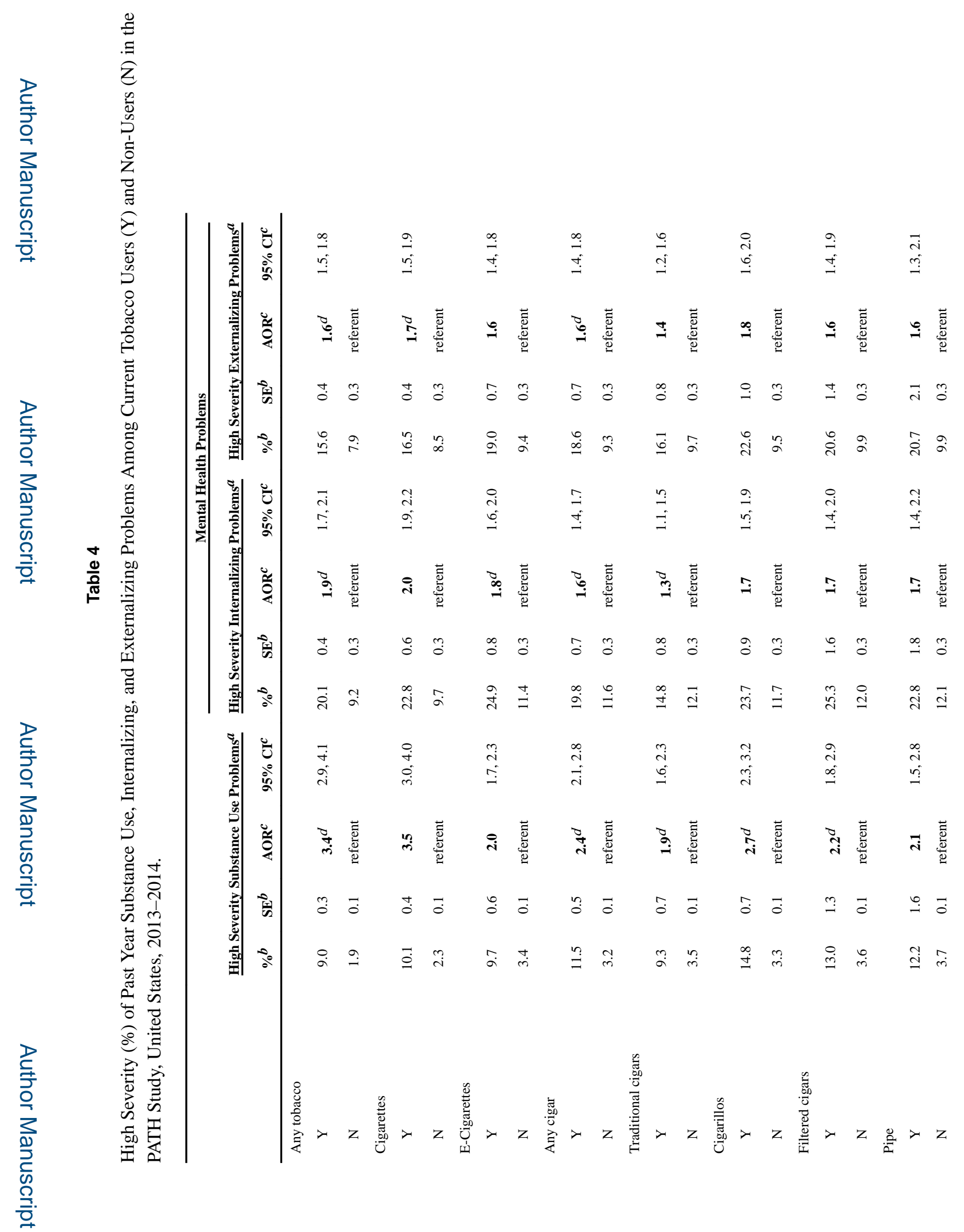

Drug Alcohol Depend. Author manuscript; available in PMC 2018 August 01. 


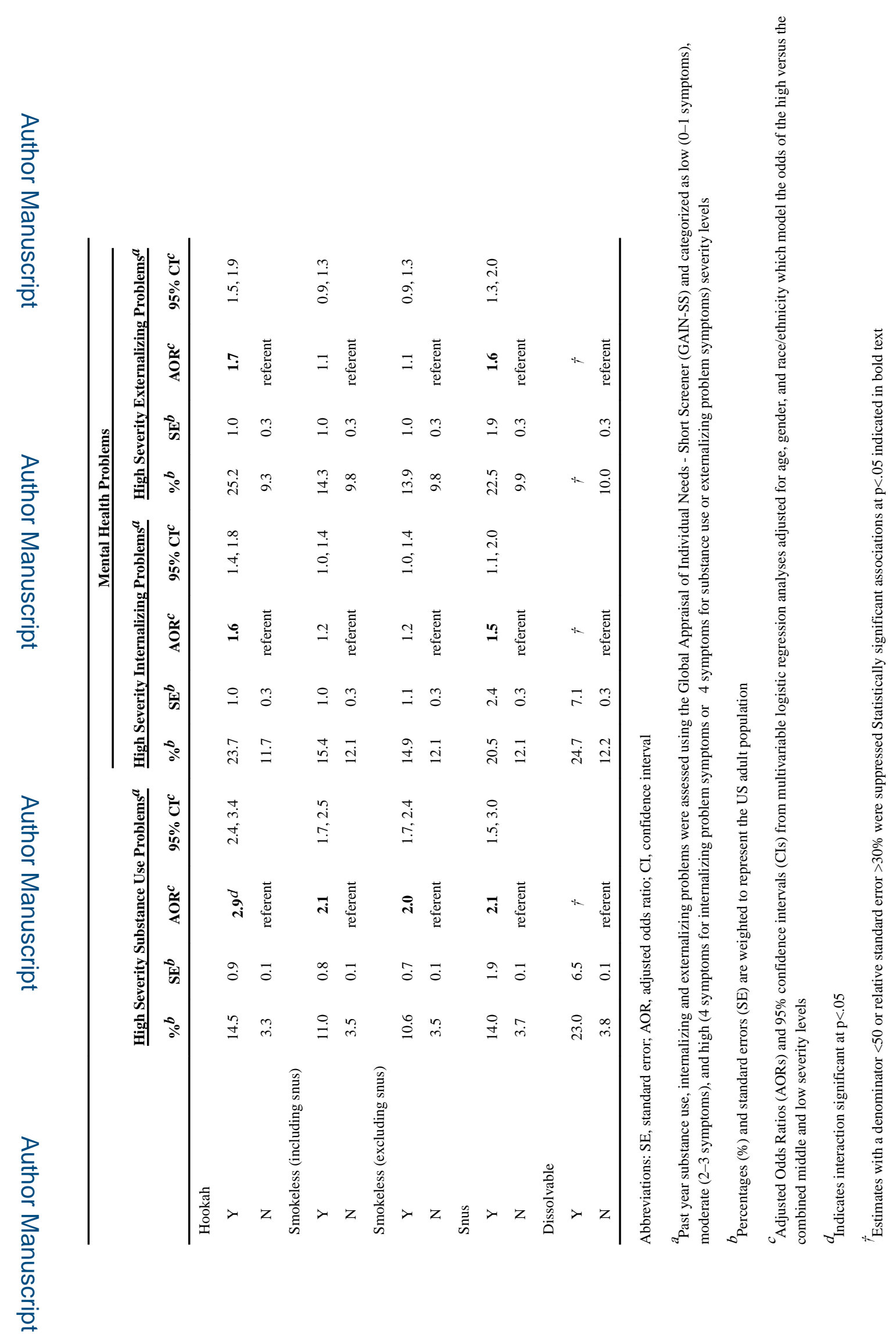

Drug Alcohol Depend. Author manuscript; available in PMC 2018 August 01. 